\title{
Athletic Training and Physical Therapy Junior Faculty Member Preparation: Perceptions of Doctoral Programs and Clinical Practice
}

Jessica L. Barrett

Springfield College, jbarrett3@springfieldcollege.edu

Stephanie M. Singe

University of Connecticut, stephanie.m.singe@uconn.edu

Aynsley Diamond

University of Connecticut, aynsley.diamond@uconn.edu

Follow this and additional works at: https://nsuworks.nova.edu/ijahsp

Part of the Physical Therapy Commons, Scholarship of Teaching and Learning Commons, and the Sports Sciences Commons

\section{Recommended Citation}

Barrett JL, Singe SM, Diamond A. Athletic Training and Physical Therapy Junior Faculty Member Preparation: Perceptions of Doctoral Programs and Clinical Practice. The Internet Journal of Allied Health Sciences and Practice. 2020 Jan 01;18(3), Article 4.

This Manuscript is brought to you for free and open access by the College of Health Care Sciences at NSUWorks. It has been accepted for inclusion in Internet Journal of Allied Health Sciences and Practice by an authorized editor of NSUWorks. For more information, please contact nsuworks@nova.edu. 


\title{
Athletic Training and Physical Therapy Junior Faculty Member Preparation: Perceptions of Doctoral Programs and Clinical Practice
}

\begin{abstract}
Background: Institutions of higher education suffer from a shortage of appropriately prepared faculty members in athletic training and physical therapy programs. Both professional programs have recently undergone curricular reform and degree change. We sought gain an understanding of the preparation mechanisms experienced by athletic training and physical therapy practitioners for their junior faculty positions. Method: Twenty-six athletic trainers and physical therapists participated in this phenomenological study. Data from one-on-one phone interviews were analyzed following the inductive process of interpretive phenomenological analysis. Content experts, pilot interviews, multiple analysts and member checking ensured trustworthiness. Results: Findings indicate two primary mechanisms prepared the practitioners to become junior faculty members: doctoral degree programs and clinical practice. Doctoral degree programs did not provide experiences for all future faculty roles. Hands-on patient care practice provided participants the context for their teaching and confidence in knowledge aptitude. Conclusion: Doctoral institutions should provide a variety of hands on active learning experiences to doctoral students. Future faculty members can maximize the amount of time they provide clinical care to patients, following the attainment of their professional credential. Clinical competence and proficiency will serve as the foundational basis for their future teaching endeavors and may increase credibility and respect.
\end{abstract}

\section{Author Bio(s)}

Jessica L. Barrett, PhD, ATC is an Assistant Professor of Athletic Training in the Department of Exercise Science and Sport Studies at Springfield College in Springfield, MA.

Stephanie M. Singe, PhD, ATC, FNATA is an Associate Professor in the Department of Kinesiology at the University of Connecticut in Storrs, CT.

Aynsley Diamond, Ed.D is the Director of Faculty Development Programs at the Center for Excellence in Teaching and Learning at the University of Connecticut in Storrs, CT. 


\title{
IVAHSP \\ The Internet Joumnal of Allied Health Sciences and Practice
}

Dedicated to allied health professional practice and education

Vol. 18 No. 3 ISSN 1540-580X

\section{Athletic Training and Physical Therapy Junior Faculty Member Preparation: Perceptions of Doctoral Programs and Clinical Practice}

\author{
Jessica Barret ${ }^{1}$ \\ Stephanie M. Singe ${ }^{2}$ \\ Aynsley Diamond ${ }^{2}$ \\ 1. Springfield College \\ 2. University of Connecticut \\ United States
}

\begin{abstract}
Background: Institutions of higher education suffer from a shortage of appropriately prepared faculty members in athletic training and physical therapy programs. Both professional programs have recently undergone curricular reform and degree change. We sought gain an understanding of the preparation mechanisms experienced by athletic training and physical therapy practitioners for their junior faculty positions. Method: Twenty-six athletic trainers and physical therapists participated in this phenomenological study. Data from one-on-one phone interviews were analyzed following the inductive process of interpretive phenomenological analysis. Content experts, pilot interviews, multiple analysts and member checking ensured trustworthiness. Results: Findings indicate two primary mechanisms prepared the practitioners to become junior faculty members: doctoral degree programs and clinical practice. Doctoral degree programs did not provide experiences for all future faculty roles. Hands-on patient care practice provided participants the context for their teaching and confidence in knowledge aptitude. Conclusion: Doctoral institutions should provide a variety of hands on active learning experiences to doctoral students. Future faculty members can maximize the amount of time they provide clinical care to patients, following the attainment of their professional credential. Clinical competence and proficiency will serve as the foundational basis for their future teaching endeavors and may increase credibility and respect.
\end{abstract}

Key Words: constructivism, professional socialization, patient care, active learning 


\section{INTRODUCTION}

Junior faculty members must be prepared for the demands of their position. ${ }^{1}$ For athletic training and physical therapy education programs' junior faculty members, this means being a knowledge expert, practitioner in their field, and one who is able to transmit their knowledge to their students. ${ }^{2}$ To date, multiple authors in the professions of physical therapy, athletic training, nursing, and occupational therapy have articulated a lack of appropriate preparation for junior faculty members. ${ }^{3-14}$ This is particularly startling for the athletic training and physical therapy professions, as both have documented a lack of appropriately prepared faculty members coinciding with an increased need for faculty members during degree and curricular changes. ${ }^{3-6,8-811,15} \mathrm{~A} 2001$ study of athletic trainers with doctoral degrees determined that education programs needed more doctoral trained individuals to fill their positions and called for the creation of more programs to be designed specifically to train practitioners who wish to work in higher education. ${ }^{9}$ This call-to-action does not appear to have generated sufficient faculty members as publications in subsequent years continued to articulate the lack of doctoral prepared junior faculty members.11,16

Because of the transition to the Doctor of Physical Therapy (DPT) degree, physical therapy programs are also facing an increased demand for qualified doctoral trained physical therapists to teach. ${ }^{15,17}$ The physical therapist faculty member is in a particularly challenging situation. ${ }^{4}$ Their accreditor, the Commission on Accreditation in Physical Therapy Education (CAPTE), requires all faculty members to hold doctoral degrees. CAPTE differentiates between an academic doctorate degree and doctoral preparation..$^{18}$ The academic doctorate is defined as requiring advanced work in a post-master's degree with the preparation of a defense or other project based on original research, while doctoral preparation is defined as a doctorate degree including the DPT. ${ }^{18}$ The accreditors also mandate education programs to maintain a mix of individuals with each degree with a minimum of $50 \%$ meeting the requirements of the academic degrees. Aggregate faculty data for physical therapy education programs in 2016 show that over $45 \%$ of faculty members have a PhD with another $14 \%$ holding a different doctorate degree such as an $\mathrm{EdD}$ or a DSc. This suggests that within physical therapy, many faculty members are earning their terminal degrees. ${ }^{18}$ However, the report also indicated that there were 141 current vacancies in faculty positions. Although physical therapists are earning their terminal degrees, it is not enough to fill the demand. $19,20 \mathrm{An}$ analytic report of athletic training programs provides data on the doctoral preparation for those in administrative positions (61\% of program directors and $32 \%$ of clinical coordinators), but does not provide data for other faculty members. ${ }^{21}$

Commonly, future educators receive pedagogical training during their graduate education. ${ }^{8}$ Exposure to the roles and demands of a faculty member begins when doctoral students, who wish to become educators, experience aspects of their graduate programs such as classes about pedagogy, curriculum development, teaching and/or learning.2,9,13,22 Those wishing to become junior faculty members must be familiarized with teaching roles and the implementation of learning strategies. ${ }^{1,23}$ Possessing an in-depth knowledge about teaching and learning is advantageous for future faculty members. ${ }^{2,22}$ Graduate students, with a career goal of becoming a junior faculty member, can learn the teaching role through opportunities to teach during their doctoral program. ${ }^{2}$ Hertel et al9 described the importance of teaching experience, "Athletic training doctoral students should be given ample training and practice in performing both classroom and clinical instruction during graduate school." "(p55) At this time, it is unknown if this is occurring in graduate education programs in athletic training and physical therapy. If junior educators are not prepared to understand the depth and breadth of a faculty position, authors in athletic training have questioned: How can they succeed as a faculty member? ${ }^{16}$

Learning about the role of teaching is only one facet of a faculty position. Graduate students who hope to become a faculty member may be aware of the tripartite responsibilities of scholarship, teaching, and service associated with such positions. However, they were likely not responsible for engaging in all three of those facets during their doctoral degree program. ${ }^{16}$ Further, they may be asked to engage in clinical practice or take on an administrative role as added responsibilities within their faculty position. An emerging theme regarding faculty preparation is that doctoral programs focus more heavily on research preparation and completion of the dissertation rather than learning teaching roles and understanding the service or administrative components of higher education. ${ }^{16,24,25}$ In physical therapy, the lack of qualified administrators to lead programs has been identified. ${ }^{15,26}$ The lack of leadership, difficulties recruiting qualified faculty members, and high turnover rate for administrators have been blamed on poor preparation of educators coupled with limited administrative experiences or exposure..$^{15,26}$

Difficulties for educators continue to emerge as the preparation of faculty and their abilities to contend with all that is required in their role is called in to question. ${ }^{16}$ Hertel et al identified athletic trainers with doctoral degrees felt teaching classes, performing research, and administrative and leadership skills were the most important aspects of their preparation for their roles. ${ }^{9}$ As such, they proposed doctoral training should include classroom teaching along with the expansion of clinical knowledge and administrative and research training. ${ }^{9}$ Though such items have been identified as important, doctoral students report they are not prepared to handle these responsibilities when entering a junior faculty academic role. ${ }^{27}$ Recent data examining the experiences of doctoral students determined they were provided with opportunities to gain skills in the scholarship aspect of higher education, but had limited chances for teaching, administrative, and service work. ${ }^{28}$ 
A review of the literature revealed there are few published studies that focus on evaluating the experiences and perceptions of practitioners who choose to become educators in athletic training and physical therapy relating to their doctoral preparation and transition to junior faculty member. Given the impact allied health professionals have on the well-being and health of their patients, understanding the educational background of these individuals can help to determine best practices in preparation of highly qualified faculty members. Therefore, the purpose of this study was to gain a better understanding of the preparation experience for athletic training and physical therapy practitioners who have received an academic doctoral degree and are newly employed in a faculty role. We specifically sought to answer the research questions: How do junior faculty in athletic training and physical therapy describe their experiences of professional socialization? Do athletic trainers' and physical therapists' experiences of professional socialization differ?

\section{METHODS}

\section{Participants and Setting}

Participants are junior faculty members, a term denoting a faculty member at the level of Assistant Professor who has not, yet, earned tenure. Individuals from the fields of physical therapy and athletic training were targeted as these allied health professions are aligned with similar education and accreditation requirements. Participants were identified following emails to the Program Directors of all Commission on Accreditation in Physical Therapy Education (CAPTE) accredited physical therapy education programs at the Doctor of Physical Therapy (DPT) level and Commission on Accreditation of Athletic Training Education (CAATE) accredited athletic training programs at both the professional bachelor and master degree levels. The email requested the Program Directors forward a second email and informational page to any junior faculty member in their department who fit the inclusion criteria. The inclusion criteria were 1) employment in a full-time faculty position in a CAPTE or CAATE accredited program for 1-4 years, 2) tenure track or eligible for reappointment, and 3) earned academic doctoral degree. Upon receipt of the informational email the junior faculty members were prompted to email the researchers directly if they were interested in participating. Potential participants were screened to ensure alignment with the inclusion criteria. Upon confirmation of meeting the inclusion criteria individual telephone interviews were arranged.

Twenty-six participants completed interviews, 13 physical therapists ( 7 male/ 6 female) and 13 athletic trainers ( 4 male/ 9 female). The average age for all participants was $37( \pm 6.3)$ years old. The average age of physical therapist participants was 3.6 years older than the average age of the athletic trainers. All participants held academic degrees, 21 participants had earned PhD degrees, and 5 had EdD degrees. Physical therapy faculty had an average of 1.5 more years in their current positions than athletic training faculty. Physical therapy participants also, on average, had 1 more year of experience teaching as a faculty member than the athletic training faculty. Furthermore, the physical therapists reported an average of 5.5 more years of full-time clinical experience prior to taking their full-time faculty position than the athletic trainers. However, only athletic trainers indicated having completed clinical-based graduate assistantship positions. The athletic training participants reported $2.7( \pm 1.5)$ years of a clinical-based graduate assistantship. Though the physical therapists did not indicate ever holding a clinical-based graduate assistantship, they were more likely to have completed teaching or research assistantships and reported an average of 1 year of more in such positions than the ATs. Table's 1 + 2, (Physical Therapist and Athletic Trainer Previous Work Experience) contain complete information regarding participants prior work experience.

Table 1. Physical Therapist Work Experience

\begin{tabular}{cccccc}
\hline Pseudonym & $\begin{array}{c}\text { Current } \\
\text { Position, } y\end{array}$ & FT Teaching, y & $\begin{array}{c}\text { Teaching } \\
\text { Assistantship or } \\
\text { Adjunct, } y\end{array}$ & FT Clinical, y & $\begin{array}{c}\text { Clinical } \\
\text { Assistantship, y }\end{array}$ \\
\cline { 3 - 6 } Cole & 4 & 0 & 4 & 18 & 0 \\
Maria & 3.5 & 3.5 & 1 & 28 & 0 \\
Roger & 1 & 3 & 6 & 6 & 0 \\
Celeste & 3 & 3 & 8 & 2 & 0 \\
Ethan & 1 & 1 & 5 & 0 & 0 \\
Geneva & 3 & 7 & 0 & 12 & 0 \\
Tom & 3 & 0 & 4 & 5 & 0 \\
Sydney & 3.5 & 3 & 0 & 10 & 0 \\
Jackson & 3 & 0 & 5 & 6 & 0 \\
Taylor & 4 & 7 & 4 & 15 & 0 \\
Sam & 3 & 6 & 0 & 1 & 0 \\
Renee & 2 & 2 & 6 & 0 & 0 \\
Joy & 1 & 0 & 2 & & 0 \\
\hline
\end{tabular}

(c) The Internet Journal of Allied Health Sciences and Practice, 2020 
Table 2. Athletic Trainer Work Experience

\begin{tabular}{|c|c|c|c|c|c|}
\hline \multirow[b]{2}{*}{ Pseudonym } & \multirow[b]{2}{*}{$\begin{array}{c}\text { Current Position, } \\
\mathbf{y}\end{array}$} & \multicolumn{4}{|c|}{ Experience prior to current position } \\
\hline & & FT Teach, y & $\begin{array}{c}\text { Teaching } \\
\text { Assistantship or } \\
\text { Adjunct, y }\end{array}$ & FT Clinical, y & $\begin{array}{c}\text { Clinical } \\
\text { Assistantship, } \\
y\end{array}$ \\
\hline Salma & 1.5 & 1.5 & 2 & 4 & 4 \\
\hline Danica & 1 & 2 & 2 & 7 & 1 \\
\hline Max & 2 & 2 & 2 & 5 & 2 \\
\hline Samar & 1 & 1 & 3 & 0 & 3 \\
\hline Elint & 2 & 3 & 2 & 0 & 3 \\
\hline Ava & 2 & 2 & 4 & 0 & 4 \\
\hline Rachel & 1 & 3 & 3 & 0 & 2 \\
\hline Vidal & 1 & 2 & 4 & 0 & 5 \\
\hline Kira & 1 & 1 & 4 & 4 & 2 \\
\hline Lee & 2 & 2 & 0 & 9 & 0 \\
\hline Janelle* & 1 & 0 & 0 & 0 & 2 \\
\hline Hakeem & 1 & 1 & 5 & 0 & 2 \\
\hline Amiya & 3 & 0 & 3 & 3 & 5 \\
\hline
\end{tabular}

†currently works in a dual-role position, (clinically and teaching) *served 22 years in a dual-role position, (clinically and teaching)

\section{Procedures}

A qualitative phenomenological methodology was followed for this study. Using a qualitative approach was appropriate, as it allowed us to explore and understand the experiences of participants who have firsthand knowledge of the given process. ${ }^{29}$ Using the participants' own viewpoint, we were able to describe the meaning they associated with the phenomenon of preparation for becoming a junior faculty member. ${ }^{29.30}$

Participants completed a one-time telephone interview following an interview guide which included informed oral consent. Interviews were digitally recorded and transcribed by a professional transcriptions company. The interview guide was developed through adaptation from previous research..$^{27,31}$ Content experts from the fields of athletic training, physical therapy, and faculty development evaluated the interview guide to ensure its alignment with the purpose statement and research questions. The content experts confirmed alignment of the instrument to the study aims and provided suggestions based on question construction and ordering. Upon approval from the Institutional Review Board, the interview guide was piloted prior to data collection with one individual in athletic training and one in physical therapy, meeting the inclusion criteria, to ensure appropriate order, flow and understanding of the questions. ${ }^{32}$ No changes were made to the interview guide following the pilot interviews. Pilot data was not used in the final analysis.

\section{Data Analysis}

Data were analyzed following a multi-step inductive process, the specific methodological framework of interpretive phenomenological analysis (IPA). ${ }^{30,33}$ The inductive analysis process allowed us describe the lived experiences and perceptions of the participants through the creation of linked categories and themes derived from the data set. ${ }^{30,33,34}$ We read each transcript attentively, moving on to build upon our understanding of the phenomenon by comparing successive transcripts to the previous ones. ${ }^{30,35}$ We coded segments of data, which identified the categories and themes that related to the research question..$^{36}$

Throughout the immersion and coding processes a list of codes was maintained on a code tree that was eventually sorted into categories based on the similarities of each code. $33,37,38$ Coding was deemed complete when no new codes were generated in reading successive transcripts, thus saturation was achieved..$^{36}$ Coded segments in each category were then pulled from the individual transcripts, and compiled, labeled and described to define their meanings. ${ }^{33}$ This allowed us to identify connections between categories and the emerging structure of themes. ${ }^{30}$

To diminish researcher bias and to add rigor to this study, the following credibility strategies were used: expert review, multiple analyst triangulation and member checking. ${ }^{36,39}$ The expert review consisted of three experts with experience engaging in research related to faculty preparation evaluated the data collection instrument in conjunction with the research design and research questions to verify alignment. Multiple researchers, 2 AT and 1 PT, then analyzed and verified the findings by reviewing the data, coding structure, and organization of final themes. The researchers first completed the analysis process individually then exchanged and discussed their findings. We were able to come to a consensus regarding the final organization of themes. Using multiple researchers with backgrounds in both physical therapy and athletic training, ensured the themes identified within each group, were verified separately, eliminating bias of a single researcher. ${ }^{36}$ Finally, member checking was completed by sending the results to participants for confirmation of their experiences. 


\section{RESULTS}

Two areas emerged from the data analysis related to athletic training and physical therapy faculty member's descriptions of the preparatory socialization experiences related to their junior faculty member role. The first, doctoral preparation contains the categories of focused preparation and limited preparation. The junior faculty members were most thoroughly prepared for the scholarship and teaching portions of their current faculty role but inadequately prepared for the administrative and service components of their positions. The second area of clinical practice describes the experiences junior faculty members had prior to or concurrent with their doctoral preparation related to hands-on patient care (see Figure 1). Please note that for the results and discussion, participants were assigned pseudonyms to protect their anonymity.

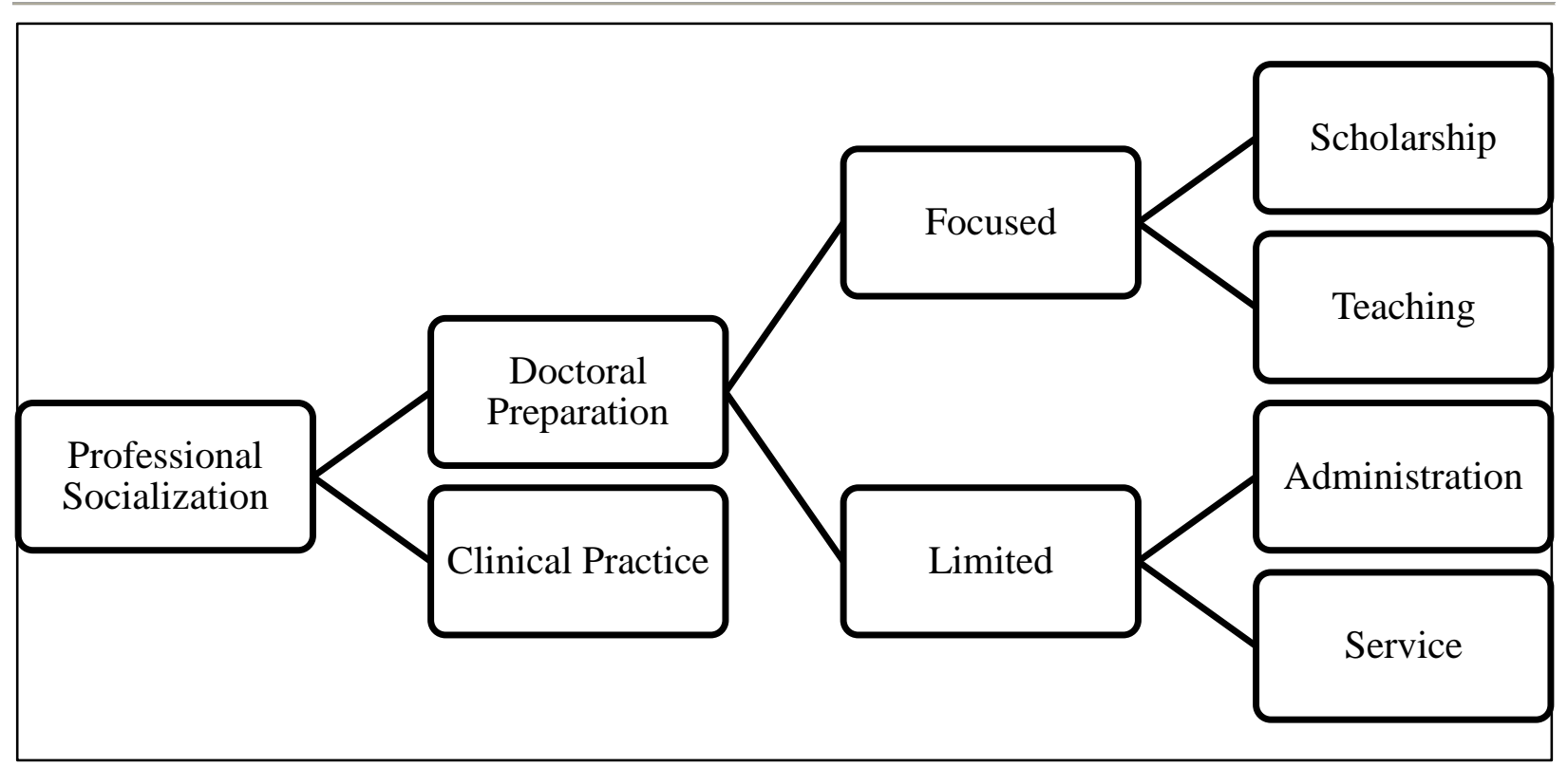

Figure 1. Professional Socialization Influences

\section{Doctoral Preparation}

Doctoral preparation provided a variety of exposures and opportunities designed to prepare junior faculty in athletic training and physical therapy. Rachel, an athletic trainer, stated of her doctoral program, "I believe that it prepared me for my position. It prepared me to be a faculty member." Two specific areas emerged as those where the junior faculty member's preparation was more focused: scholarship and teaching. Further, faculty members who had gained exposure in their doctoral degree programs to their current roles and responsibilities related to teaching and scholarship also often reported feelings of comfort and satisfaction when they were completing those roles in their current positions. The roles for which they had more experience were those in which they were more comfortable and confident completing.

\section{Focused Preparation - Scholarship}

Doctoral preparation best prepared the junior faculty members in this study for the research requirement of their faculty position. Eighteen (18) participants discussed preparation experiences related to scholarly endeavors during the pursuit of their academic doctoral degree. More physical therapy participants were exposed to research responsibilities than athletic training participants. Twelve (12) of the 13 physical therapy participants currently have research requirements as a part of their faculty position, whereas only 8 of 13 athletic training participants have research requirements in their current role (see Figure 2). In discussing her research preparation, Celeste a physical therapist said, "I think I was well prepared for that. I mean to managed projects, do the analysis, do collaboration if needed. All these things I think I was well prepared because we were very independent in the PhD." She later continued discussing how her research preparation impacted her job selection and her level of comfort on the job, saying "I just love research. I would not be as comfortable in a job where it's only teaching or service. I, of course, don't mind teaching and service it's just that I wouldn't do it 100 percent of my time."

Elin, an athletic trainer reported a similar situation when talking about her line of research she said, "My PhD definitely helped, I would say overall it helped find my niche and kind of make me unique in what I know and what I focus on." She continued specifically referencing her research, 
Really, it's driving my current research, if I didn't do what I did in my grad (school) I would not have the research agenda that I currently have. l've gotten a few grants, been able to collaborate and really drive my research. If you don't have a solid foundation, moving forward with that, you're gonna really struggle.

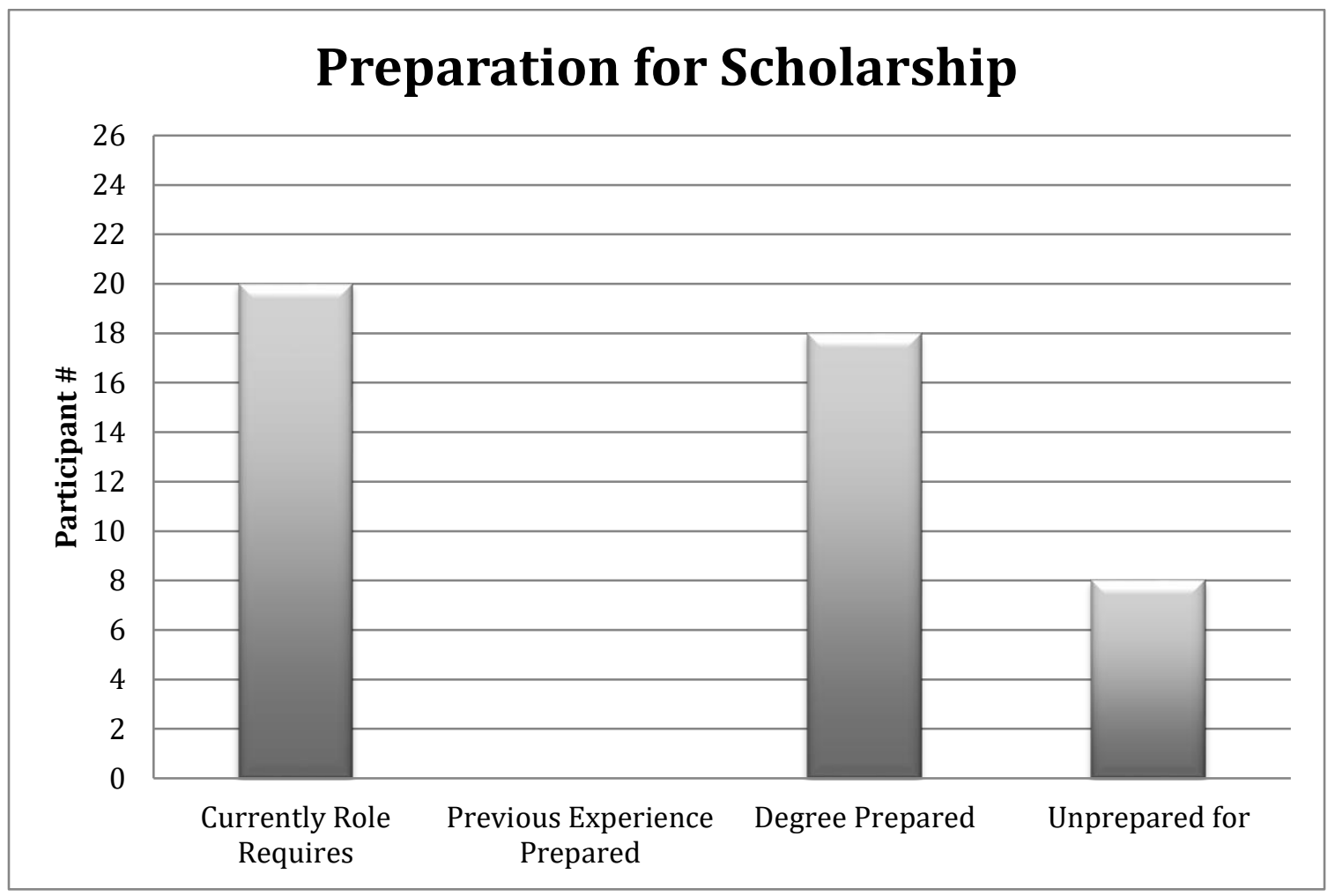

Figure 2. Preparation for Scholarship

Roger, a physical therapist, also discussed the heavy influence of research in his doctoral program and how it has influenced his junior faculty position. Of his doctoral program he said, "I would say definitely in developing and organizing and then completing you know publishable and fundable research projects. I think it prepared me." He went on to say in his current position, "I enjoy the research the most right now," and when asked what portion of his position he was most comfortable in he said, "Oh the research for sure. I think it's because I am the most prepared for that to be honest." For the junior faculty members in this study, their doctoral preparation was filled with scholarship experiences that allowed them to develop confidence in the research process and assisted them in generating their own line of inquiry. This strong foundation allowed them to begin their junior faculty positions with a plethora of experiences to draw on and a firm understanding of the requirements for engaging in scholarly activity.

\section{Focused Preparation - Teaching}

The second area where junior faculty members were provided professional preparation was for the role of teaching. Sixteen participants discussed preparation experiences within their academic doctoral degree program related to their teaching role. Five other participants indicated they were prepared for their teaching role because of experiences they sought out on their own concurrent with their doctoral degree. For those five participants, teaching assistantships were not available in their graduate programs, but they were able to teach as an adjunct in a different program or nearby school during their graduate studies. All the participants had teaching requirements as a part of their current faculty positions (see Figure 3).

Rachel, an athletic trainer, described the beneficial aspects of her EdD curriculum, saying

So, with the actual coursework in my "major," that was classes like preparing to be a professor and kind of like figuring out time management, how to create a syllabus, how to structure classes. There were classes about the college students, classes about assessments, student development theories. It was educational so it was very educationally-based." 


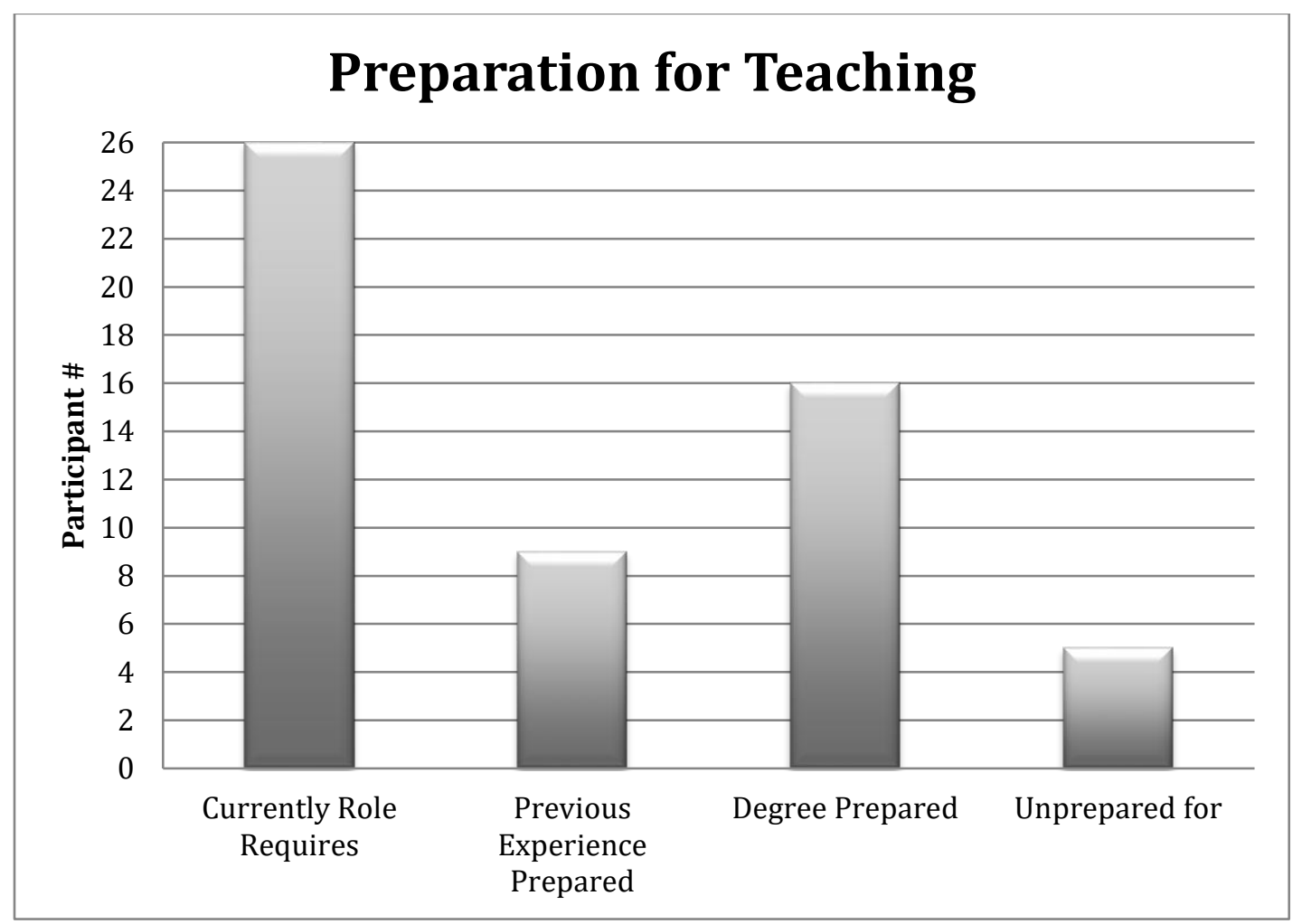

Figure 3. Preparation for Teaching

Rachel's program contained many aspects of teaching that were immediately useful in her junior faculty role. Other participants also sought out teaching-related coursework some of which was outside of their degree program's. Samar, shared, "I did take a few classes that were related to teaching. They weren't necessarily part of my program. I sought them out. And those have helped me quite a bit, actually, in my current role." Similarly, Jackson, a PT, described seeking an elective program to enhance his teaching knowledge in his doctoral program, stated

I did a teaching certification on the side, which was a one-and-a-half-year program. That was not a part of the curriculum. At the time I was in the program that was not required even though we had teaching practicums and all. And I did a teaching practicum, which got me interested into more of this certification course. But that was health professions educator certificate offered by school of nursing. I probably was a teaching assisting for almost five years in that program.

Jackson later stated that learning throughout the certificate program and working as a teaching assistant were considerably beneficial experiences to draw from as he moved into his junior faculty position. He said,

I think it's been much easier to transition into the teaching role, from getting teaching certificate program and professional educator certificate. At least it gave a snapshot of what to expect and how people do the things. I think being a TA (teaching assistant) also definitely helped me prepare for this. So, yes, at least have an idea that this is what you're going to do, on how exactly and what are the steps to it.

For many other participants, the preparation for teaching within their doctoral degree programs came from teaching experiences. When asked if his $\mathrm{PhD}$ program prepared him for his faculty role, Hakeem, an athletic trainer, said, "Oh, absolutely. So the experience of the teaching, that prepared me to be teaching in the first semester here since I joined." Ethan, a physical therapist, described his teaching experiences that were concurrent with his $\mathrm{PhD}$ training, saying

I think starting with my third year; I started helping out in the medical school classes, the medical school neuroscience lab. There was a gross dissection component with that and then also some online computer-based sessions. I think it 
was the spring semester each year I would just help out with that. I wasn't paid for it or anything like that, but just got a little bit of experience there of at least answering student questions and helping guide people along.

Ethan went on to state later that, "I would definitely say that the teaching component is what I'm most comfortable with." The experiences he sought to gain exposure to teaching resulted in assisting his transition to his junior faculty position, as he was comfortable with that component of his job.

Joy, a physical therapist, shared her experiences teaching in her PhD program as both a teaching assistant and as an instructor of record.

It varied from year to year, depending, I was a GA that was assigned to the physical therapy program, so I assisted, I assisted in classes in the graduate physical therapy program. And then I was instructor of record for at least one term when we had a faculty member that left. It was an introductory class that I was qualified to teach so I was the instructor of record.

When asked if she felt her PhD program prepared her for her current faculty position, she reflected on the importance of that teaching experience saying,

I do, it was, they gave me the opportunity to be a TA and teach. So, the teaching aspect, I feel more comfortable with, like, being, you know, preparing stuff for class and getting up and lecturing, just because I had done it before in the PT, in this PT program.

Kira, an athletic trainer, also shared information about the beneficial impact of having her own classes rather than acting as a teaching assistant:

I taught six credits each semester for my entire time. I was the instructor of record. I think having my own standalone course where I had to design my own syllabus and content for teaching. I know a lot of people don't have the same type of experience, so for me it was a very easy transition to just step into my own class.

Participants who had taken teaching related coursework or who participated in teaching experiences within their doctoral degree programs felt prepared to handle those responsibilities upon acceptance of their junior faculty positions.

\section{Limited Preparation - Administration and Service}

Unfortunately, doctoral preparation did not prepare the junior faculty members for all their future roles. The two areas where junior faculty members receive deficient training for their current roles were in administrative responsibilities and service initiatives. When faculty members were asked to engage in a role for which they did not receive ample training, they discussed feeling uncomfortable or were dissatisfied with their contributions to that portion of their position. Nine physical therapy faculty members and ten athletic training faculty members identified feeling that their doctoral degree program did not prepare them for the administrative aspects of their current positions or described a lack of content related to those responsibilities in their doctoral programs (see Figure 4).

Similarly, a lack of exposure to service opportunities within their doctoral preparation was noted by 20 participants. However, 22 participants had service responsibilities as a part of their current position (see Figure 5).

Interestingly, only two physical therapy faculty members reported having an assigned administrative leadership role in their current position. Both PT junior faculty members with administrative roles cited their previous experiences as clinicians to have been beneficial in handling their responsibilities. The professional socialization area of prior experiences is described in depth below. The lack of administrative preparation for athletic training faculty is quite different as eight athletic training junior faculty members are currently engaged in an administrative role. Lee, an AT program director felt his doctoral program was deficient in preparing him for the key administrative responsibilities of his junior faculty position, "

For instance, in my doctoral program, we didn't go over how to be a clinical coordinator, how to be a program director, how to look at standards, how to write an annual report, we didn't look at those things. And yeah, turning out they are super important. 
The 2020 Standards for Accreditation of Professional Athletic Training Programs, as determined by the Commission on Accreditation of Athletic Training Education, have identified minimum qualifications for program directors related to degree level and previous experience, though at the time of this research, these standards had not been released.

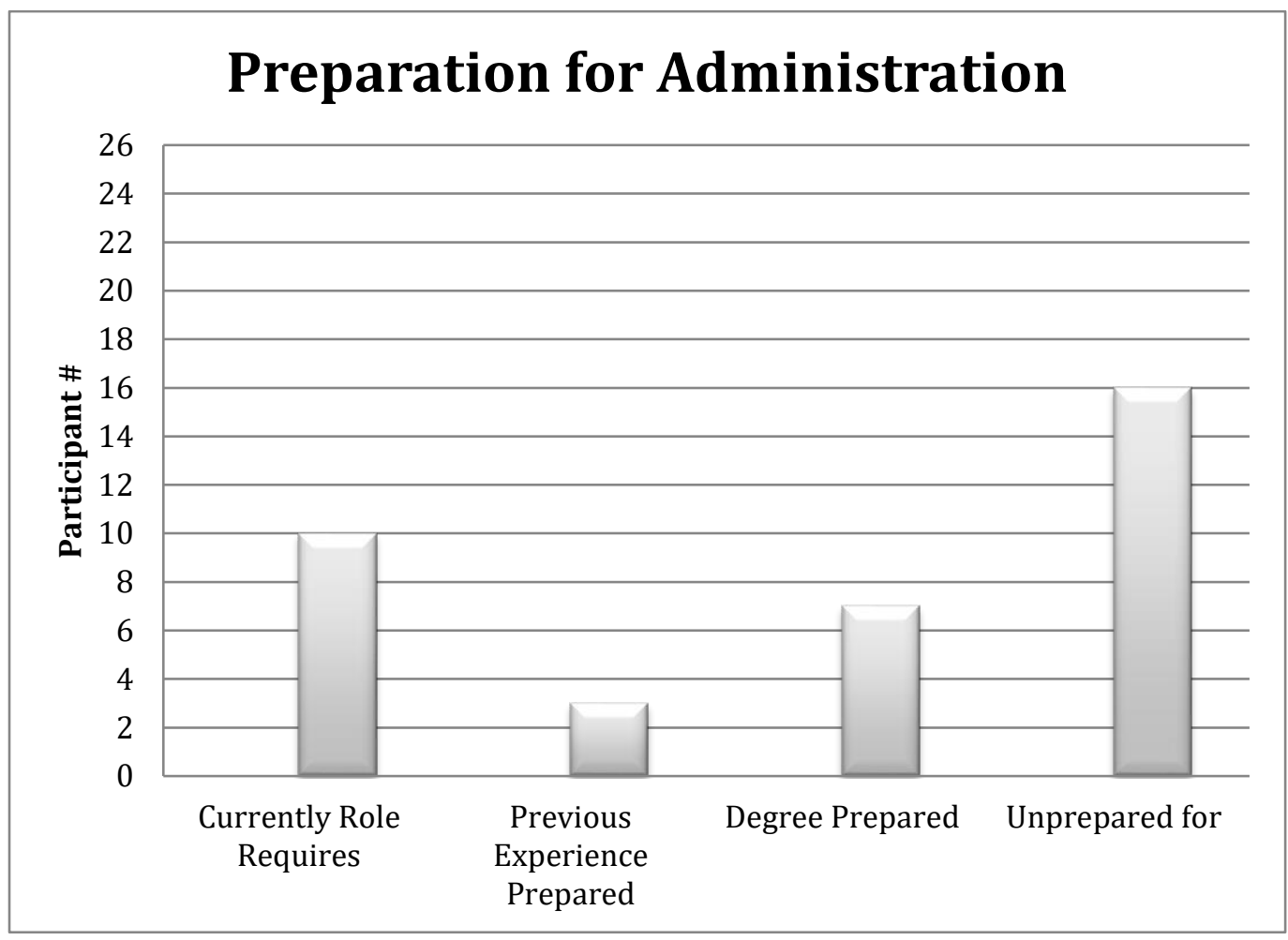

(Figure 4. Preparation for Administration)

The lack of experience and exposure to the administrative roles and responsibilities during their doctoral programs put the junior faculty members at a disadvantage. Ava, an AT program director and clinical coordinator, felt very unprepared for the administrative tasks of her junior faculty position,

I think the one thing that I missed out a little bit of is just the general administration. You know, I've dealt with day-to-day stuff as a clinical coordinator for the grad program during my $\mathrm{PhD}$. I dealt with orientation and things like that, but I never had to deal with the actual uploading of documents, maintaining the documents, and dealing with the self-study or enter reports and things like that for CAATE. I never did that. So, when I got here, it was a little bit of a crash course trying to make sure that everything is uploaded and correct and all this other stuff.

Taylor, a PT, described a lack of exposure to administrative and service components in his PhD program, "Those components were mostly optional and voluntary because, as I mentioned, the focus of the program was just to prepare the students to be researchers." The result of this lack of preparation for Taylor meant that he relied upon his colleagues for help in his junior faculty position. When he was asked what aspects of his position were least satisfying, he said,

Mostly the curricular committee work, for which I needed to be mentored. I received mentoring after I joined this current position. To do what I need to do here. Service is probably my least favorite just because sometimes it puts me in a zone which l'm not comfortable with and which l'm not really trained to. 


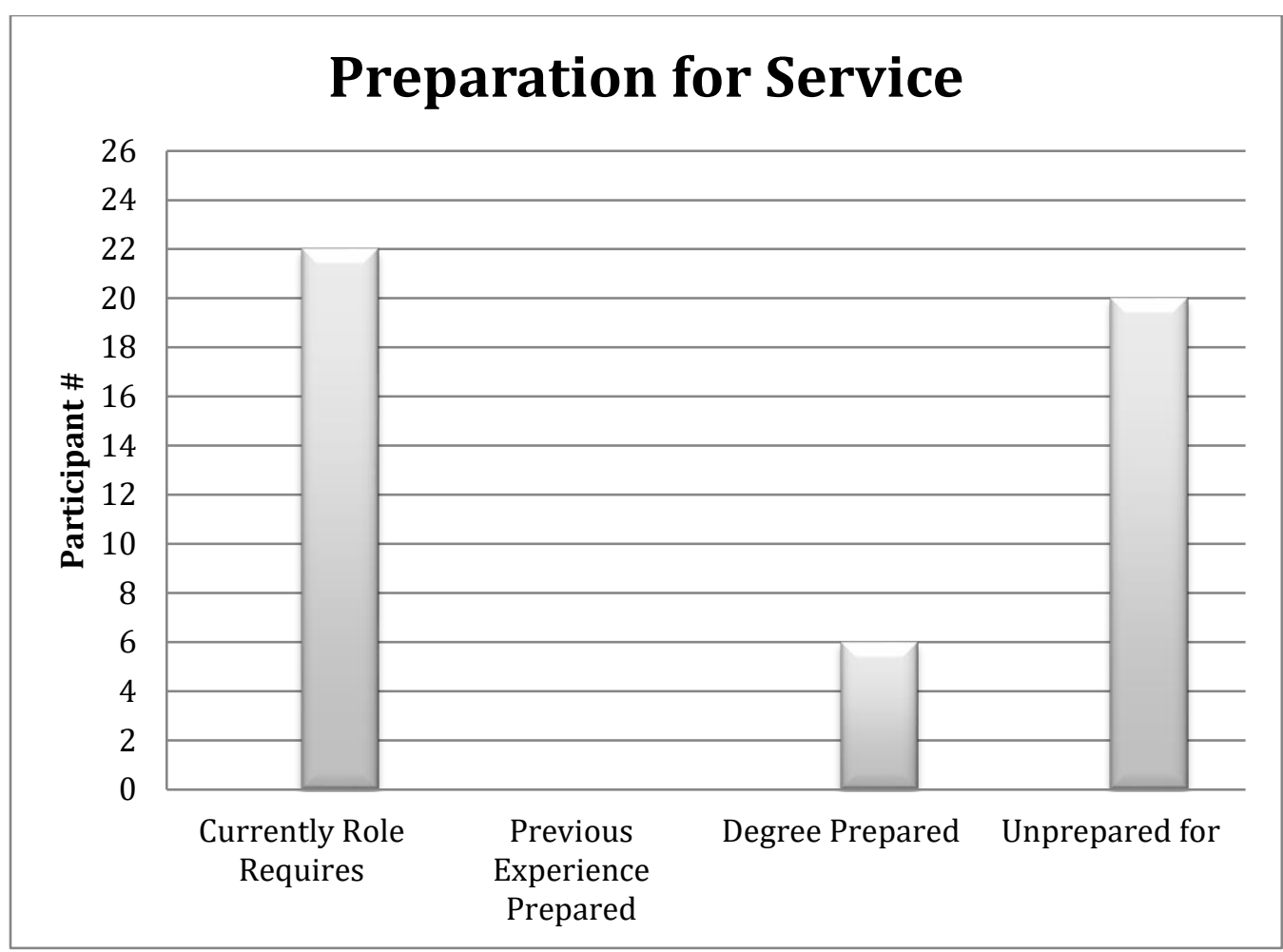

Figure 5. Preparation for Service

Many faculty members described a similar cycle in which they did not receive training in the tasks they were expected to fulfill as faculty members and therefore were unprepared and unaware of how to handle those responsibilities. Similarly, when asked what she would change about her doctoral training Samar said,

I think I would have pursued more opportunities to learn about program administration. My current role has a lot of that, and I didn't feel prepared. And I still, after a year, don't necessarily feel prepared all the time to handle the things that I do every day.

When asked about the most challenging aspects of her position Samar said, "I'm most challenged by the administrative aspect, for sure."

In addition to the lack of exposure to administrative components, service aspects were particularly challenging for junior faculty members. Geneva a PT said there were, "Not service projects within the program." Similarly, Joy, a PT, stated, "I don't think my PhD, specifically prepared me for the service component." Tom, a PT, when asked if he felt his PhD prepared him for his position stated, "No, I had no clue about all of the committees that were involved with the University and how much time does take away from your day-to-day activities." He further explained the most challenging aspect of his position, "Service. I think there's a disconnect, especially at this university of what real service is." Understanding even the definition of service and how to fulfill that role was difficult for the junior faculty members who had no previous experiences to draw upon. Hakeem, an AT, stated that he was the most uncomfortable with performing the service component of his faculty position. He further explained, "The service is a new area. I've been contributing but have a lot of things to learn and understand. So that's why maybe least [comfortable]."

\section{Clinical Practice}

The second socializing agent, which became apparent during analysis, is the participant's explanation of their clinical practice as a professional socialization experience. Clinical practice speaks to the importance the junior faculty members placed on their experiences as practitioners prior to their full-time faculty role. Fourteen participants identified their work as clinicians, prior to beginning their current position, as influential in informing their current faculty roles. Seven physical therapy participants maintain clinical practice responsibilities in their current positions, while only 1 athletic trainer maintains such a role. Nine participants specifically identified that their prior years of experience working as clinicians directly impacted their ability and confidence related to teaching. Additionally, the two physical therapists who are currently engaged in administrative roles described their prior clinical 
experiences were more formative than their doctoral training in preparing them for their administration position. Janelle, an athletic trainer, also felt her prior experiences were more beneficial than her doctoral program in preparing her for administrative duties. When asked if her doctoral program prepared her for her current position she said,

Gosh, that's a hard thing to say because a lot of what prepared me for my position is 20 years of doing it prior to having it [the terminal degree]. I mean, the doctorate had nothing to do with me being able to be an effective program director.

She described the importance of junior faculty members having a background in clinical practice,

I'm all for the program directors having to have years of experience clinically before becoming program directors. Because I think going from the bachelor's to the master's to a PhD, the program director doesn't do service to our profession and to the students.

And later added,

I think that's huge that people actually go through and work clinically before they become program directors because that validates what you're doing and that gives you credibility of the students. So, I think that's important.

Janelle identified that her years of experience as a practitioner in the field were quite formative, giving her experience to draw from, as well as validation and respect. Correspondingly, Ethan a physical therapist, shared his regret that he did not have more clinical experience, when asked if he would change anything about pursuing his doctoral degree he said,

I definitely would have practiced a few years before going into my $\mathrm{PhD}$ program. At the time, I thought I really wanted to do the research and I liked the research, but looking at it from the perspective now, I wish I would have had the insight to say, you know, this will benefit you later on in life to have more clinical experience.

Ethan also shared advice he now gives his students,

I know l've definitely counseled one of my students to... we've talked about how she might be interested in doing a PhD at some point. I counseled her and told her that in my opinion, I think it would be better to practice at least for a few years. You get a little bit more perspective and you can at least just have that on your CV, be able to back up a little bit more the things that your teaching in the classroom. It's not that I don't understand those things, it's not that I don't understand how they're applied in the physical therapy world but being able to have more patient examples would be great.

Janelle, Ethan and many other participants identified the spending time as a practitioner provides valuable work experiences that will assist faculty members in performing as teachers and administrators. Likewise Maria, also a physical therapist shared,

You want to keep seeing patients because I think that helps with your teaching. Do you want to bring the clinical side to your teaching? It has helped me a lot with teaching gerontology and orthopedic treatment because such a large part of any practice these days is working with older adults.

Finally, Kira, an athletic trainer with 4 years of full-time clinical experience remarked upon that time saying, "I knew the importance of having clinical practice behind you to be able to give real world experience and talk about things you've seen rather than just repeat what the textbook says." For many athletic training and physical therapy junior faculty members, their years of clinical experience gave them examples to draw from when teaching and enhanced their ability to make educational material relevant to their students.

\section{DISCUSSION}

In this study, we set out to gain a better understanding of the preparation process for athletic training and physical therapy practitioners who are newly engaged in a faculty role. Two areas impactful to professional socialization emerged from the data analysis: doctoral preparation and clinical practice. Participants described their doctoral education programs focused more time on scholarship and teaching preparation than on the administrative and service components. They also described their years of experience as practitioners provided them with content knowledge and valuable experience, which also assisted in preparing them for their faculty role. 


\section{Doctoral Preparation}

The athletic training and physical therapy participants in our study were prepared by and had experienced aspects of their future faculty role during their doctoral studies. The two areas that were particularly focused on throughout doctoral preparation were research and teaching. Our participants discussed their confidence executing their research and teaching roles in their new positions because many had already gained exposure to performing those roles. A 2016 study of athletic trainers working in higher education found that the majority of the professional socialization for faculty members had occurred within doctoral programs. ${ }^{40}$ The population identified in that study had an average of more than 11 years of experience working in higher education, which is higher than our participants. ${ }^{40}$ However, both populations discussed their reliance on their doctoral training for their initial understanding of their faculty role. Additionally, Mazerolle et al similarly identified that research and teaching were the two areas in which the athletic training faculty members were best prepared by their doctoral programs. ${ }^{40}$ The participants cited the "authentic experiences" they participated in throughout their doctoral programs, in the areas of teaching and research assistantships, to have been quite helpful in their preparation for their current positions in higher education. ${ }^{40(p .213)}$ This same level of preparedness in research and teaching was found in both our physical therapy and athletic training participants. Like the previously studied educators, for our participants, their exposure to the roles of teaching through graduate assistantships and their experience with performing research projects and working in laboratory settings throughout their doctoral degree prepared them to take on their junior faculty positions with confidence.

The doctoral degree setting provides a logical place to for learning to occur among students who wish to become educators. In an educational context, learning can occur for future faculty members by participating in teaching activities while placed in a supportive classroom environment where they can receive feedback. ${ }^{41}$ Such an environment will help future faculty members understand how their preparation directly translates to their future job. ${ }^{41}$ This was certainly the case for our participants. Participants Rachel and Jackson identified their doctoral program curriculums and classroom experiences assisted their teaching preparation. Ethan, Kira and others expressed the importance of teaching assistantships and instructor's roles that allowed them practice for their future faculty role.

In addition to providing experience, another feature that has been proposed to improve the preparation of educators is placing an increased focus on the implementation of educational theory. ${ }^{42}$ Within the fields of athletic training and physical therapy, researchers have determined the implementation of theory is missing in educator preparation.6,43 Theoretical foundational understanding can allow new educators to understand the existing knowledge base related to teaching and learning, which will assist them in making better sense of the processes they observe in their own classrooms. A theory that has previously been identified as aligning with athletic training, physical therapy, and nursing fields is constructivism. ${ }^{43-46}$

The theoretical implications of constructivism can be applied to teaching and learning in athletic training and physical therapy to assist in the development of junior faculty members. ${ }^{43,46}$ The primary aspect of constructivist education is student immersion in various applications of learning new information to allow the construction of new knowledge. ${ }^{45} \mathrm{New}$ material can be learned by building on existing foundational knowledge through the sharing of previous experiences in new applications, which can lead to the development of new knowledge..$^{43}$ For example, in the clinical experience settings of athletic training and physical therapy education, students build upon knowledge learned in the classroom when they are able to practice and apply those skills in reallife patient encounters. For graduate students seeking roles as educators, the building of foundational knowledge should occur through learned material in coursework, which is then enacted and applied in a teaching assistantship. Understanding the importance of education theory provides the link to between gaining classroom knowledge and having the opportunity demonstrate that knowledge by teaching or performing research in a supported setting.

The connection between having experiences in the roles of teaching and research and having confidence in completing those roles can be explained through a combination of constructivist education and adult learning principles (andragogy). Constructivist theory applies to athletic training and physical therapy education using constructivist learning in clinical and classroom settings, along with the emphasis on learning over time. Students are able to continually integrate old and new ideas to enhance (construct) their learning in didactic and hands-on situations. ${ }^{43}$ Adult learning becomes important to understand, as students enrolled in doctoral programs are adults, which prompts a change in teaching philosophy from pedagogy to andragogy. As adults, these students bring a variety of previous experiences to their doctoral programs, and are older and more mature than undergraduate students ${ }^{45}$. Knowles, the primary developer of andragogy, describes the principles of adult learning also allow the learner to build upon previous experiences and construct new knowledge. ${ }^{47}$ Both adult learning and constructivist education theory value the prior knowledge students bring to learning situations. The theory of constructivism provides a framework that blends well with adult learning theory ${ }^{45}$ which is evidenced in the ways our participants learned the roles of teaching and research.

Adult learners prefer learning environments and activities that allow them to maintain their independence and act in a self-directed manner while sharing their own experiences and learning from others. 45,48 Our participants described teaching standalone courses

(c) The Internet Journal of Allied Health Sciences and Practice, 2020 
and earning teaching certificates as ways in which they were able to learn and enact their future role, which assisted in their transition to that role. Pitney provides an example of a novice clinician observing and learning skill application from a seasoned professional in an article which links andragogy and athletic training. ${ }^{49} \mathrm{~A}$ similar example is seen in the experiences of our participants. Those who had the opportunity to engage in professional preparation for their teaching and research roles were able to learn from others in the lab and classroom, creating foundational experiences for them to build upon in their future profession. As doctoral students, when our participants were able to engage in active learning tasks within the teaching and research areas, they were more prepared and comfortable enacting what they had learned when they were subsequently asked to perform them in their jobs. Following this line of reasoning, it is not surprising that those areas where doctoral students lacked exposure and engaging experiences left them feeling less confident and unsuccessful.

Kreber has documented suggestions for graduate programs to adequately prepare future educators. ${ }^{42}$ The suggestions include the integration of courses on pedagogy in the graduate program curriculum, the opportunity to act as teaching assistants, and the provision of a basis of educational theory to give context to learning. 42 The importance of teaching assistantships was described in relation to the learning principles of andragogy. The importance of educational theory implementation was also described in relation to constructivism.

With regards to the integration of coursework in doctoral programs, there are examples in the literature deciphering the benefits of such inclusion. Within athletic training, according to a survey of students, teaching quality was better amongst their instructors who had taken coursework in pedagogy. ${ }^{22}$ Further, these students perceived increased effectiveness from their teachers who had taken 10 or more courses related to education. ${ }^{22}$ Similarly, in a survey of athletic trainers working in the college setting, taking a course in teaching methods was one of two factors found to predict confidence in understanding teaching methodologies. ${ }^{2}$ These two studies align with Kreber's suggestion on the importance of teaching preparation.

We did not specifically ask our participants to identify courses related to teaching that they experienced, but many shared they had taken such coursework, some as electives beyond their degree requirements. Previous findings and the suggestions of Kreber, coupled with our findings, show that for junior faculty to be confident in their positions and function as effective educators their doctoral programs included coursework focused on teaching and learning and opportunities to practice teaching. 2,22,42 If a student is situated in a graduate school or department where there are no courses available related to teaching, they can look to related departments or schools such as a college of education for coursework related to curriculum or teaching methods. ${ }^{16}$

\section{Clinical Practice Preparation}

Clinical practice was the second mechanism by which our participants explained their professional socialization experience. Physical therapists reported an average of 5.5 more years of full-time clinical experience prior to taking their teaching positions than the athletic trainers. However, the athletic trainers reported participating in an average of 2.7 years of clinical -based graduate assistantships, whereas physical therapists did not report participating in those positions. Taking the graduate assistantship years into account closes the years of clinical experience gap substantially. The age differences between our two groups of participants could be another reason the physical therapists demonstrated more years of experience clinically. The average age for the physical therapists in our study was 3.6 years older than the average for the athletic trainers. Considering the physical therapy degree is achieved beyond an initial bachelors' level undergraduate degree, it is logical that an athletic trainer would gain their professional credential and being practicing at a younger age than a physical therapist.

In a study of novice physical therapists, in their first two years of clinical practice, the age range for participants was $24-29.50$ For a study of novice athletic trainers, identified as engaged in a graduate assistantship, their age range was 23-47 with a median of 24. ${ }^{51}$ This study indicated that graduate assistant athletic trainers are novice's practicing autonomously for the first time. Participants in the study indicated they sought out mentors for assistance but encountered difficulty finding mentors because of the limited availability of their supervisors. ${ }^{51}$ Interestingly, those who supervise athletic training graduate assistants have suggested that the population lacks some professional behaviors and skills when they transition to autonomous clinical practice; they are not fully prepared. ${ }^{52}$ Communication skills were among the greatest areas where the supervisors thought improvement in novices was needed. ${ }^{52}$ This is similar to findings of novice physical therapists in their first year of clinical practice that also acknowledged the need to grow and develop communication skills. ${ }^{53}$

Within athletic training graduate assistant supervisors, it was also noted that novice practitioners were unable to completely practice independently and fully execute their roles; thus, they relied upon mentors and support of colleagues. ${ }^{52}$ Again, novice physical therapists echo similar findings as they too prefer a supportive environment that encourages their growth through mentorship and allows them to build confidence as they transition to full-time clinical practice. ${ }^{53}$ Given the similarities in the initial years as a novice practitioner, it appears that athletic trainers and physical therapists are similarly prepared for their clinical experiences. Physical therapists who are experienced clinicians have been found to function with greater confidence in their positions as a result of the 
large amount of knowledge they have gained throughout their years of working. ${ }^{54}$ This high level of knowledge and confidence was specifically evident as it related to interpreting information from patients and using that information to make a clinical decision. Novice practitioners are less confident in their ability to make clinical decisions or predict positive clinical outcomes. ${ }^{54}$

A recent editorial in the Athletic Training Education Journal identified that athletic training program faculty seem to be poorly prepared in the area of clinical practice. ${ }^{55}$ Yet, a study by Payne et al indicated that athletic training educators utilize their prior clinical practice experiences to enhance the classroom content they teach. ${ }^{6}$ In that study, the educators had at least eight years of teaching experience, were an average of 45.5 years old, and had been BOC certified for an average of 22.73 years. ${ }^{56}$ Our athletic training participants had an average of 3.1 years of teaching experience, were an average of 35 years old, and had 5.2 average years of clinical experience as a credentialed athletic trainer. Though they were younger with less experience than the educators in the Payne et al study, they too indicated their clinical experience was beneficial to them in the classroom providing content knowledge and confidence; just as our participants noted. .6

A recommendation by Payne et al encouraged doctoral students and those interested in becoming future faculty member's to attempt to gain clinical practice experience prior to taking a faculty position. ${ }^{66}$ This suggestion was made based on the heavy workload that is present in academia for junior faculty members, making it challenging to maintain clinical practice once in that position. Challenges for junior faculty members work-load has been identified as they contend with heavy teaching loads, scholarly productivity, service initiatives, and clinical practice, all of which they are often unprepared to balance. $.3,4,13,16$

Some of our participants identified the problematic nature of continuous sequential schooling whereby a student moves along their academic track never gaining significant time in full-time clinical practice. Ethan and Janelle both shared their feelings regarding the importance of spending time in hands-on practice. For many of our participants, time in clinical practice assisted their teaching and helped them feel confident and respected. However, curricular changes and the focus on hiring doctoral prepared individuals may prompt those interested in academic positions to forgo time as a practitioner after earning their practice credential and encourage them to immediately begin their next academic phase. ${ }^{20}$ Some of our participants, both athletic trainers and physical therapists followed that path.

A model has been proposed in physical therapy to connect all components of an individual's education from professional preparation through the earning of a PhD while still including time for clinical practice. ${ }^{19}$ This integrated approach described by Arena et al describes identifying those applying for the DPT who wish to eventually earn a PhD and work in higher education. ${ }^{19} \mathrm{In}$ this proposal, those individuals would first gain training and credentialing as a practitioner (the DPT), then partake in clinical practice while potentially earning an advanced specialty certificate or a residency in addition to beginning to earn credits toward their PhD. This "DPT-Residency-PhD" track emphasizes the importance of clinical practice following the initial credentialing prior to engaging in a full-time faculty role. The $\mathrm{PhD}$ is earned while clinical practice is maintained; required research projects would likely be entrenched in their clinical practice. This type of program echo's the importance of clinical practice in the preparation of future educators that was identified by the participants in our study.

While this type of program may work for physical therapy, it may not be possible in athletic training because of scheduling issues and funding. The authors mentioned the clinical practice by those on the track generated the revenue that was used to fund their positions, a cycle that currently does not exist in athletic training where billing is not as commonplace as it is in physical therapy. ${ }^{19}$ There are currently 10 athletic training residency programs accredited by the Commission on Accreditation of Athletic Training Education. This would be an interesting path for both professions to continue investigating in addition to seeking other innovative and creative ways to adequately prepare faculty while providing them with all the necessary experiences they will need for a successful transition to their full-time faculty roles.

\section{Limitations and Recommendations for Future Research}

Our study relied upon the qualitative responses of participants. We did not analyze the junior faculty members graduate school transcripts or employment contracts. Measuring research productivity, in the form of publications or grant applications that may have been submitted during the doctoral program, were also beyond the scope of this project. Finally, teaching evaluations from the participant's time as teaching assistants were not analyzed. We did not seek the opinions of other stakeholders such as graduate student faculty advisors, dissertation committee members, or laboratory or clinical supervisors. Nor did we seek the opinions of former students or patients. Each of the above areas could be explored in the future to triangulate the findings outlined here and to further enrich what is currently known about the faculty preparation process.

\section{CONCLUSION}

Doctoral students must be exposed to all facets of a faculty position if they are to be successful upon entering the academic workforce. Our findings indicate that doctoral programs provide preparation for junior faculty members in the areas of research and teaching. However, they are less successful in exposing graduate students to the rigors of service and administrative components 
that may be necessary in their future faculty role. Following constructivist education theory and allowing doctoral students to build on their previous experiences, both from clinical practice and graduate assistantships, is a way to socialize them into their future roles. Utilizing andragogy and active learning principles by putting doctoral students in positions like those they will embody in the future will increase their confidence when they do transition to their junior faculty position. Junior faculty members report they are more confident and comfortable completing the roles for which they were prepared during their doctoral programs but lacked confidence in completing the roles they were less prepared for. Additionally, practitioners who hope to become faculty members should maximizing the opportunities they have for clinical practice prior to beginning their faculty role. This working exposure will provide the junior faculty member confidence for teaching, while also affording them with experiences that can be shared with future student. Increasing the amount of time they provide hands-on clinical care to patients, following the attainment of their professional credential, can increase their competence and proficiency.

\section{REFERENCES}

1. Steinert Y, Mann K, Centeno A:, D., Spencer J, Gelula M, Prideaux D. A systematic review of faculty development initiatives designed to improve teaching effectiveness in medical education: BEME guide no. 8. Med Teach. 2006;28(6):497-526.

2. Craig DI. Athletic training instructors: A needs assessment of teaching methodology knowledge and self-perceived competence. Athl Train Educ J. 2006;2(April-December):28-37.

3. Peterson CA, Umphred DA. A structured faculty development process for scholarship in young faculty: A case report. $J$ Phys Ther Educ. 2005;19(3):86-89.

4. Peterson CA, Sandholtz JH. New faculty development: Scholarship of teaching and learning opportunities. J Phys Ther Educ. 2005;19(3):23-29.

5. Luedtke-Hoffmann K, Peterborg L, Cross S, Rappleye H, Stafford L, Weiser L. Preparation of academic administrators in physical therapist education programs: Is more needed? J Phys Ther Educ. 2010;24(2):4-13.

6. Audette J, Roush S. Considering educational perspectives and their relevance to allied health professional education: Using physical therapy as an example. Internet Journal of Allied Health Science and Practice. 2015;13(3):Article 7.

7. Turocy PS. The impact of instructor expertise and competency on student learning and strategies for improvement. Athl Train Educ J. 2016;11(3):158-160.

8. Rich V. Employment characteristics, educational histories, and pedagogical training of educators in CAATE-accredited athletic training education programs. Athl Train Educ J. 2009;4:131-138.

9. Hertel J, West TF, Buckley WE, Denegar CR. Educational history, employment characteristics, and desired competencies of doctoral-educated athletic trainers. J Athl Train. 2001;36(1):49-57.

10. Borsa PA. Leadership in the academy: Junior faculty as program directors. J Athl Train. 2005;40(1):256-257.

11. Dewald L, Walsh K. Tenure track athletic training educators: Are they being set up to fail? Athl Train Educ J. 2009;4:114149 .

12. Smith JA, Zsohar H. Essentials of neophyte mentorship in relation to the faculty shortage. J Nurs Educ. 2007;46(4):184-186.

13. Schoening AM. From bedside to classroom: The nurse educator transition model. Nurs Educ Perspect. 2013;34(3):167-172.

14. Falzarano M, Zipp GP. Perceptions of mentoring of full-time occupational therapy faculty in the united states. Occup Ther Int. 2012;19:117-126.

15. Hinman M, Peel C, Price E. Leadership retention in physical therapy education programs. J Phys Ther Educ. 2014;28(1):3944. doi: 10.1097/00001416-201410000-00007.

16. Payne EK, Berry DC. From graduate student to professor: Reflection on the transition and tips for those who follow. Athl Train Educ J. 2014;9(2):87-93.

17. MacKinnon JL, Leighton RD. Physical therapist student interest in full-time faculty positions. J Aliedl Health. 2002;31(2):7077.

18. Commission on Accreditation in Physical Therapy Education. Standards and required elements for accreditation of physical therapist education programs. http://www.capteonline.org/AccreditationHandbook/. Updated March 16, 2016.

19. Arena R, Girolami G, Aruin A, Keil A, Sainsbury J, Phillips SA. Integrated approaches to physical therapy education: A new comprehensive model from the university of illinois chicago. Physiotherapy Theory and Practice. 2017;33(5):353-360. doi: 10.1080/09593985.2017.1305471.

20. Portney LG. 17th pauline cerasoli lecture: Choosing a disruptive path toward tomorrow. J Phys Ther Educ. 2014;28(3):4-14. doi: 10.1097/00001416-201407000-00002.

21. Commission on Accreditation of Athletic Training Education. 2015-2016 CAATE analytics report. 2017:1-41.

22. Schellhase KC. The relationship between student evaluation of instruction scores and faculty formal educational coursework. Athl Train Educ J. 2010;5(4):156-164. 
23. Morin $\mathrm{KH}$, Ashton KC. Research on faculty orientation programs: Guidelines and directions for nurse educators. $J$ Prof Nurs. 2004;20(4):239-250.

24. Gaff JG. The disconnect between graduate education and faculty realities. Liberal Education. 2002;88(3):6-13.

25. Gardner SK. Faculty preparation for teaching, research, and service roles: What do new faculty need? J Fac Dev. 2005;20(3):161-166.

26. Gordon J. Wanted: Effective academic leadership: Commentary on "Leadership retention in physical therapy education programs" by martha hinman, PT, EdD, claire peel, PT, PhD, FAPTA, and ellen price, PT, MEd. Journal of Physical Therapy Education. 2014;28(1):45-47. doi: 10.1097/00001416-201410000-00008.

27. Austin AE. Preparing the next generation of faculty: Graduate school as socialization to the academic career. J Higher Educ. 2002;73(1):94-122.

28. Bowman TG, Mazerolle SM, Klossner JK. The professional socialization of doctoral students seeking careers in athletic training. 2015; Oral Presentation.

29. Smith JA. Qualitative methodology: Analysing participants' perspectives. Clinical Psychology and Behavioral Medicine. 1996;9(6):417-421.

30. Pietkiewicz I, Smith JA. A practical guide to using interpretative phenomenological analysis in qualitative research psychology. Psychological Journal. 2014;20(1):7-14.

31. Pitney W. The professional socialization of certified athletic trainers in high school settings: A grounded theory investigation. J Athl Train. 2002;37(3):286-292.

32. Gill $P$, Treasure $E$, Chadwick $B$. Methods of data collection in qualitative research: Interviews and focus groups. Br Dent $J$. 2008;204(6):291-295.

33. Thomas D. A general inductive approach for qualitative data analysis. American Journal of Evaluation. 2006;27:237-246.

34. Pope C, Ziebland S, Mays N. Qualitative research in health care: Analysing qualitative data. BMJ. 2000;320(7227):114-116.

35. Boeije H. A purposeful approach to the constant comparative method in the analysis of qualitative interviews. Quality \& Quantity. 2002;36:391-409.

36. Bradley EH, Curry LA, Devers KJ. Qualitative data analysis for health services research: Developing taxonomy, themes and theory. Health Services Research. 2007;42(2):1758-1772.

37. Hsieh HF, Shannon SE. Three approaches to qualitative content analysis. Qual Health Res. 2005;15(9):1277-1288. doi: 15/9/1277 [pii].

38. Elo S, Kyngas H. The qualitative content analysis process. J Adv Nurs. 2008;62(1):107-115. doi: 10.1111/j.13652648.2007.04569.x [doi].

39. Barbour RS. Checklists for improving rigour in qualitative research: A case of the tail wagging the dog? British Medical Journal. 2001;322(7294):1115-1117.

40. Mazerolle SM, Barrett JL, Nottingham SL. Examining the factors that facilitate faculty socialization into higher education. Athl Train Educ J. 2016;11(4):208-218.

41. O'Sullivan PS, Irby DM. Reframing research on faculty development. Acad Med. 2011;86(4):421-428. doi: 10.1097/ACM.0b013e31820dc058 [doi].

42. Kreber $\mathrm{C}$. The scholarship of teaching and its implementation in faculty development and graduate education. New Directions for Teaching and Learning. 2001;86(79):88.

43. Peer KS, McClendon RC. Sociocultural learning theory in practice: Implications for athletic training educators. $J$ Athl Train. 2002;37(4):S136-S140.

44. Brandon AF, All AC. Constructivism theory analysis and application to curricula. Nursing Education Perspectives. 2010;31(2):89-92.

45. Peters M. Does constructivist epistemology have a place in nursing education? J Nurs Educ. 2000;39(4):166-172.

46. Behar-Horenstein LS, Hudson-Vassell C, Roberts KW, Zafar MA. Promoting physical therapists' instructional expertise and teacher efficacy. Journal of Faculty Development. 2013;27(3):49-56.

47. Knowles MS. Speaking from experience: The professional organization as a learning community. Training and Development Journal. 1979;2(4):36-40.

48. Candy PC. Constructivism and the study of self-direction in adult learning. Studies in the Education of Adults. 1989;21:95116.

49. Pitney WA. Continuing education in athletic training: An alternative approach based on adult learning theory. J Athl Train. 1998;33:72-76.

50. Hayward LM, Black LL, Mostrom E, Jensen GM, Ritzline PD, Perkins J. The first two years of practice: A longitudinal perspective on the learning and professional development of promising novice physical therapists. Phys Ther. 2013;93(3):368384.http://ezproxy.lib.uconn.edu/login?url=https://search.ebscohost.com/login.aspx?direct=true\&db=rzh\&AN $=104254914 \&$ site=ehost-live. . doi: $10.2522 /$ ptj.20120214. 
51. Mazerolle SM, Clines S, Eason CM, Pitney WA. Perceptions of support networks during the graduate-assistant athletic trainer experience. Journal of athletic training. 2015;50(12):1256. doi: 10.4085/1062-6050-50.11.09.

52. Thrasher AB, Walker SE, Hankemeier DA, Pitney WA. Supervising athletic trainers' perceptions of graduate assistant athletic trainers' professional preparation. Athletic Training Education Journal. 2015;10(4):275-286. doi: 10.4085/1004275.

53. Black LL, Jensen GM, Mostrom E, et al. The first year of practice: An investigation of the professional learning and development of promising novice physical therapists. Phys Ther. 2010;90(12):1758-1773. http://ezproxy.lib.uconn.edu/login?url=https://search.ebscohost.com/login.aspx?direct=true\&db=aph\&AN=56495579\&site=e host-live. doi: 10.2522/ptj.20100078.

54. Jensen GM, Gwyer J, Shepard KF, Hack LM. Expert practice in physical therapy. Phys Ther. 2000;80(1):28-43. http://ezproxy.lib.uconn.edu/login?url=https://search.ebscohost.com/login.aspx?direct=true\&db=aph\&AN=2724525\&site=eh ost-live.

55. Geisler PRD, C.R., Turocy PS, Martin M, et al. Mini-editorial compilation for special section. Athl Train Educ J. 2017;12(2):62-72.

56. Payne EK, Walker SE, Mazerolle SM. Exploring athletic training educators' development as teachers. Athl Train Educ J. 2017;12(2):134-145. 